\title{
ORNAMENT SZNUROWY NA CERAMICE LUDNOŚCI KULTURY AMFOR KULISTYCH Z POZNANIA-NOWEGO MIASTA (STAN. 314)
}

\author{
A CORDED ORNAMENT ON THE GLOBULAR AMPHORAE CULTURE \\ POTTERY FROM POZNAŃ-NOWE MIASTO (SITE 314)
}

\author{
Andrzej Michalowski, Andrzej Sikorski \\ Instytut Prahistorii, Uniwersytet im. Adama Mickiewicza \\ ul. Św. Marcin 78, 61-807 Poznań, Poland
}

\begin{abstract}
The article discusses a corded decoration on pottery from the Amphorae Globular Culture seasonal camp. Analysis of impressions on the pot outer surfaces revealed that this characteristic motif was produced by a simple textile template. Fragments of a five-stranded cord ( $\mathrm{S} / 3 \mathrm{~S} / 2 \mathrm{Z})$ - certainly not a two-stranded one - were sewn on a net 'band' (item of a sprang type). This technique guaranteed a precise layout and space between particular impressions (ca. $2 \mathrm{~mm}$ each) on a soft amphorae (?) surface irrespective of an angle of ornament placements and decorative element joints.
\end{abstract}

Ciaggle brakuje nam danych o tekstyliach, które najczęściej - jako organiki - nie zachowują się w źródłach archeologicznych. Szczególnie w odniesieniu do starszych epok dysponujemy tylko odciskami plecionek, siatek i znaleziskami włókienniczymi, jakie utrwaliły się na wyrobach ceramicznych. Częściej rejestruje się narzędzia służące do przygotowywania nici, ciężarki tkackie czy szpule gliniane niż „tkaniny wykopaliskowe" i wyroby pozatkackie ${ }^{1}$. Za interesujące należy więc uznać negatywy wyrobu, wykonanego w technice siatkowej i sznura, będącego charakterystycznym elementem zdobniczym na ceramice neolitycznej ${ }^{2}$.

\section{LOKALIZACJA ZNALEZISKA}

Ułamki ceramiki naczyniowej pochodzą z nadzorów archeologicznych (budowa obwodnicy miasta Poznania na odcinku autostrady A2), które przeprowadzono w $2001 \mathrm{r}^{3}$

\footnotetext{
' $\mathrm{aszczewska} 1966$, s. $21 \mathrm{n}$.

${ }^{2}$ Malinowski 1985, s. 168-172.

${ }^{3}$ Michałowski, Rogalski, Źołkiewski 2001.
} 


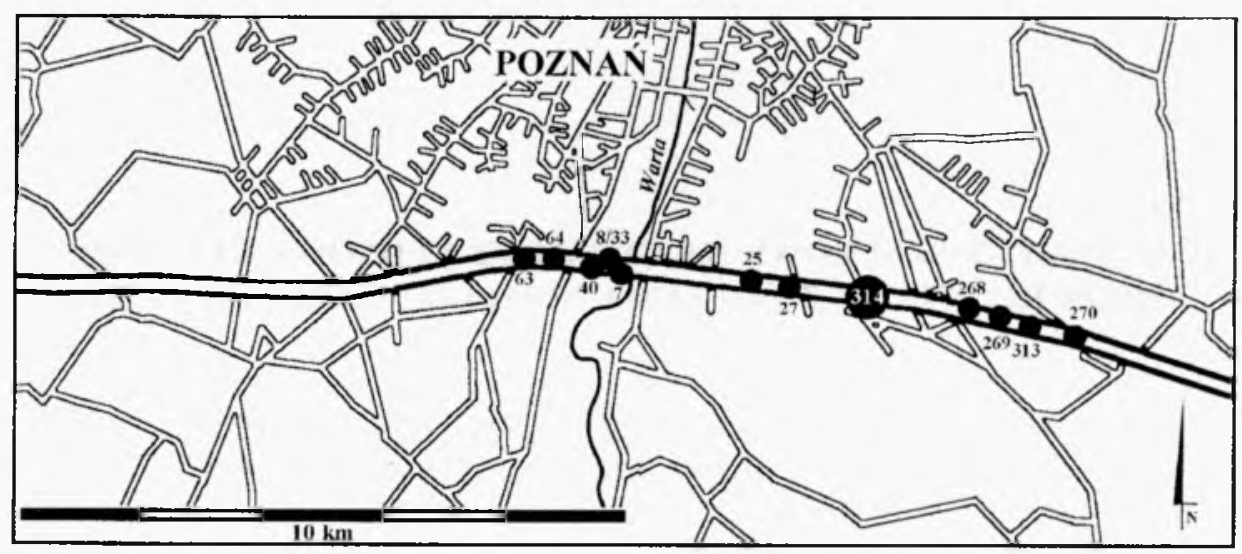

Ryc. 1. Poznań-Nowe Miasto, stan. 314. Lokalizacja stanowiska. Rys. M. Żółkiewski

Fig. 1. Poznań-Nowe Miasto, site 314. Site location. Drawing: M. Żółkiewski

Na wyznaczonym stanowisku 314, w poludniowej części, po zbadaniu ponad 40 arów, zarejestrowano tylko palenisko (o wymiarach $0,74 \times 0,53 \mathrm{~m}$ i miąższości $0,2 \mathrm{~m}-$ ryc. 2 ). W przepalonym wypełnisku, z luźno zalegającymi kamieniami (bez śladów obróbki), stwierdzono krzemienny rdzeń szczątkowy $i$ odłupek oraz 24 fragmenty ceramiki naczyniowej z trzech pojemników (o czarnej, zdobionej sznurem i brunatnej szorstkiej i gładkiej powierzchni - nieornamentowane). Przy obiekcie znaleziono także mały kamienny gładzik. Pozyskany materiał, $\mathrm{z}$ dużym prawdopodobieństwem, łączyć można z krótkotrwałym obozowiskiem ludności kultury amfor kulistych. W przypadku tego typu miejsc zachowują się tylko pojedyncze obiekty i skupiska zabytków. Mając na uwadze obszar, który został rozpoznany wykopaliskowo, wolno sądzić, iż w bezpośrednim sąsiedztwie (ryc. 1) nie było żadnych innych śladów (nie zachowały się?) pobytu tutaj rzeczonej grupy ${ }^{4}$.

\section{OPIS CERAMIKI}

Do analizy laboratoryjnej przygotowano 7 fragmentów górnej części amfory (?) ryc. 2, 11-13. Ułamki pochodzą z jednego pojemnika o grubości ścianek $(0,7-0,9 \mathrm{~cm})$, wypalonego w atmosferze utleniajacej (zewnętrzna powierzchnia ciemno-szaro-brunatna - 10YR 4/1, 4/2; wewnętrzna bardzo ciemnoszara przechodząca $w$ odcień bardzo ciemno-szaro-brunatny - 10 YR $3 / 1,3 / 2)^{5}$. Obydwie powierzchnie naczynia zagładzone, ze staranie upakowaną domieszką mineralną (granulat okraggły i ostrokrawędzisty

\footnotetext{
${ }^{4}$ Wiślański 1979a, s. 280; Michałowski, Rogalski, Żółkiewski 2001.

${ }^{5}$ Munsell 1973.
} 


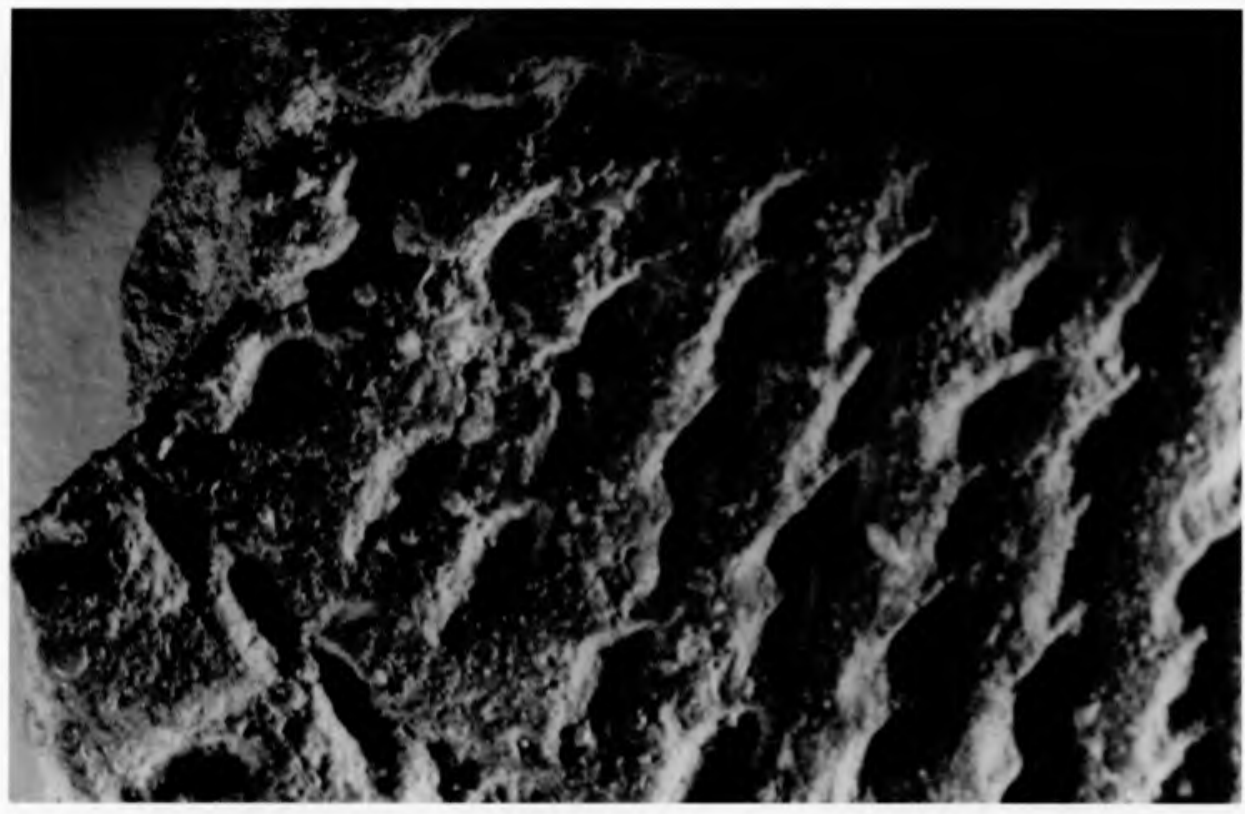

Fot. 1. Poznań-Nowe Miasto, stan. 314. Odcisk sznura na ściance naczynia. Fot. A. Sikorski Photo I. Poznań-Nowe Miasto, site 314. Cord impression of a vessel wall

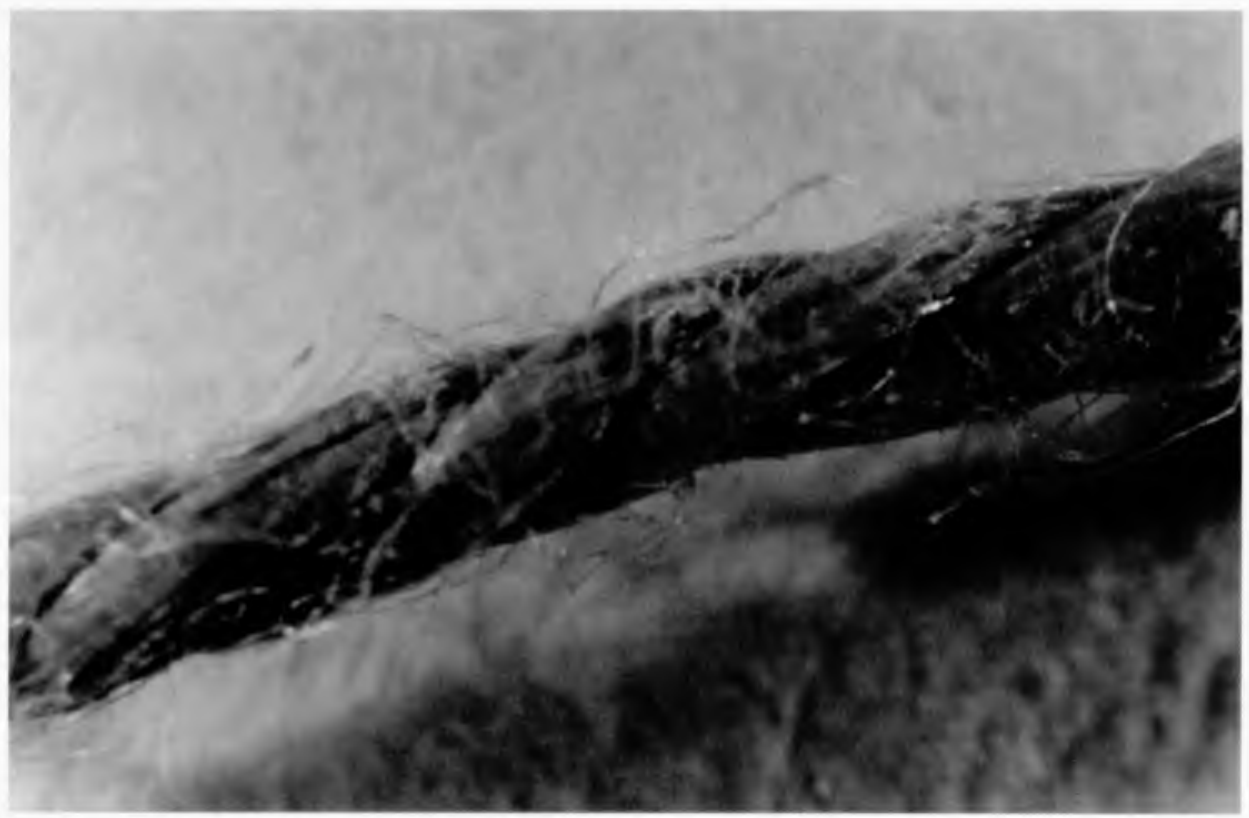

Fot. 2. Sznurek współczesny S/5Z. Fot. A. Sikorski

Photo. 2. Contemporary cord $\mathrm{S} / 5 \mathrm{Z}$ 


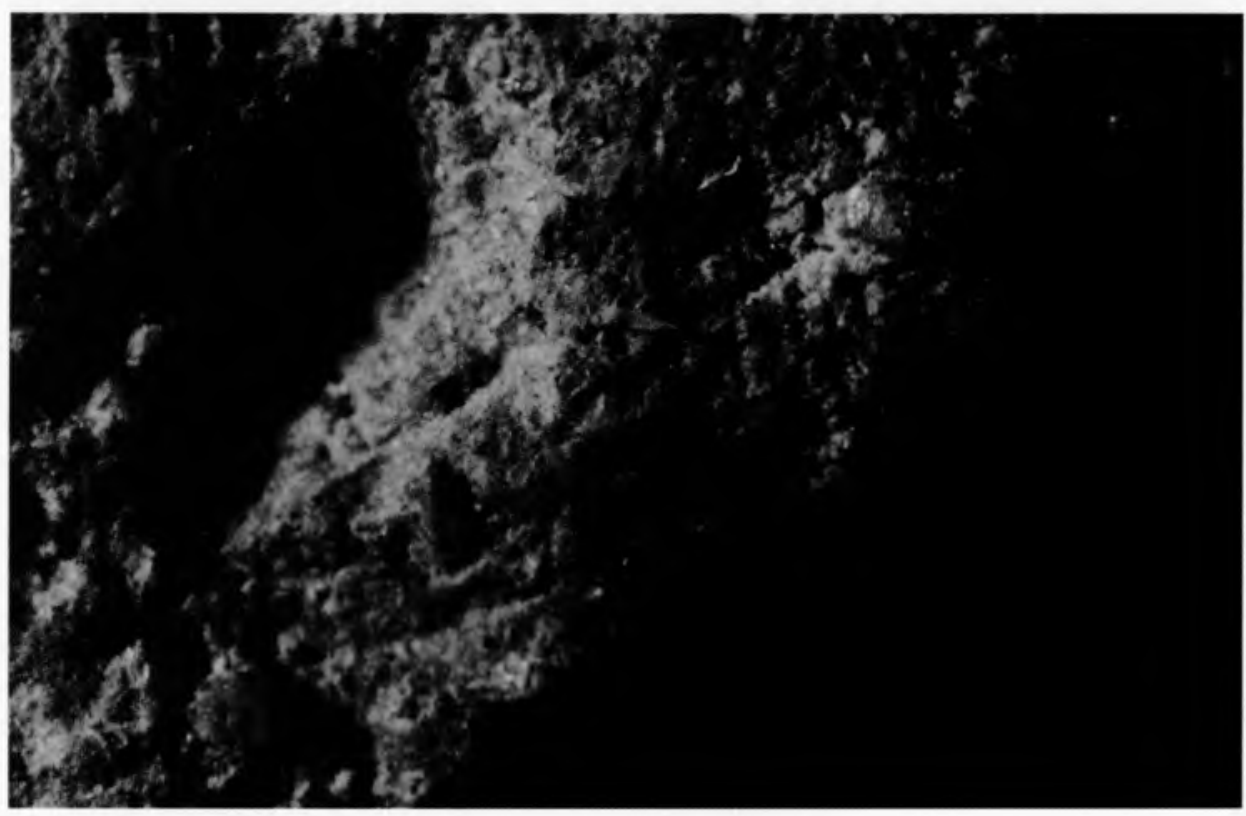

Fot. 3. Poznań-Nowe Miasto, stan. 314. Odcisk wyrobu siatkowego. Fot. A. Sikorski Photo. 3. Poznań-Nowe Miasto, site 314. Impression of a net item 

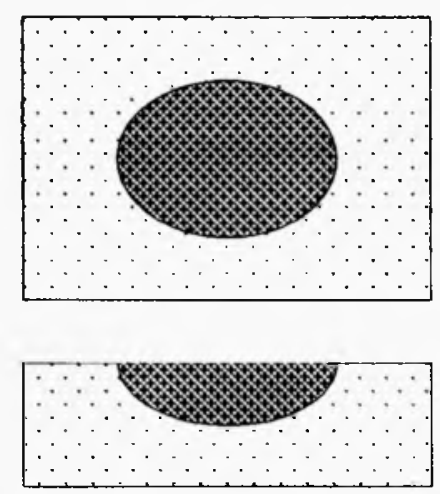

Ryc. 2. Poznań-Nowe Miasto, stan. 314, obiekt 1.

Legenda: 1 - calec; 2 - spalenizna przemieszana z próchnicą. Rys. A. Michałowski

Fig. 2. Poznan-Nowe Miasto, site 314. Feature 1. Legend: 1 - subsoil, 2 - bumt layer mixed up with humus
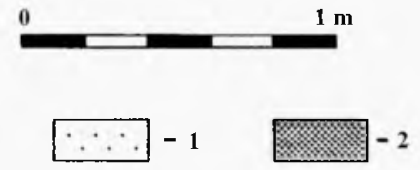

o wielkości $0,5-3 \mathrm{~mm}$ ). Na niektórych ściankach wewnętrznych rozpoznano popękaną substancję ,smolistą", która ściśle przywarla do tworzywa ceramicznego. Wątek zdobniczy, wykonany w plastycznej masie ceramicznej, brzegi głębokiego negatywu sznura (do $1,5 \mathrm{~mm}$ ) wyraźnie wygładzone.

\section{WYNIKI LABORATORYJNE}

Powyższa obserwacja uzupełniona opisem „faktów zdobniczych”6 - już na etapie analizy megaskopowej - nasunęła kilka przypuszczeń. Po pierwsze, na i w pobliżu „barokowego" zdobnictwa sznurowego (na naturalnej krzywiźnie brzuśca i szyjki) nie było żadnych odcisków palców (lub paznokci) - co przy nakładaniu sznura w odstępach co $2 \mathrm{~mm}$ (na mokrą ściankę dużego pojemnika) jest raczej nieuniknione; po drugie - zachowano precyzyjny układ i odstępy odcisków sznura niezależnie od kąta nanoszenia i styków poszczególnych elementów zdobniczych; po trzecie - faktura ścianki pomiędzy odciskami sznura wydawała się zbyt „mączysta” i równa. Chcąc wyjaśnić te kwestie, postanowiliśmy przeprowadzić serię rutynowych badań w Instytucie Biologii Środowiska UAM i Instytucie Prahistorii UAM (m.in. z zastosowaniem mikroskopu stereoskopowego NIKON SMZ 1000). Łącznie wykonano ponad 200 pomiarów i oznaczeń laboratoryjnych (tab. 1,2). Wyniki obserwacji omówimy osobno dla sznurków i wyrobu siatkowego, tworzącego swoisty szablon zdobniczy. Nie najlepszy stan zachowania

\footnotetext{
${ }^{6}$ Kośko 1981, s. 58.
} 

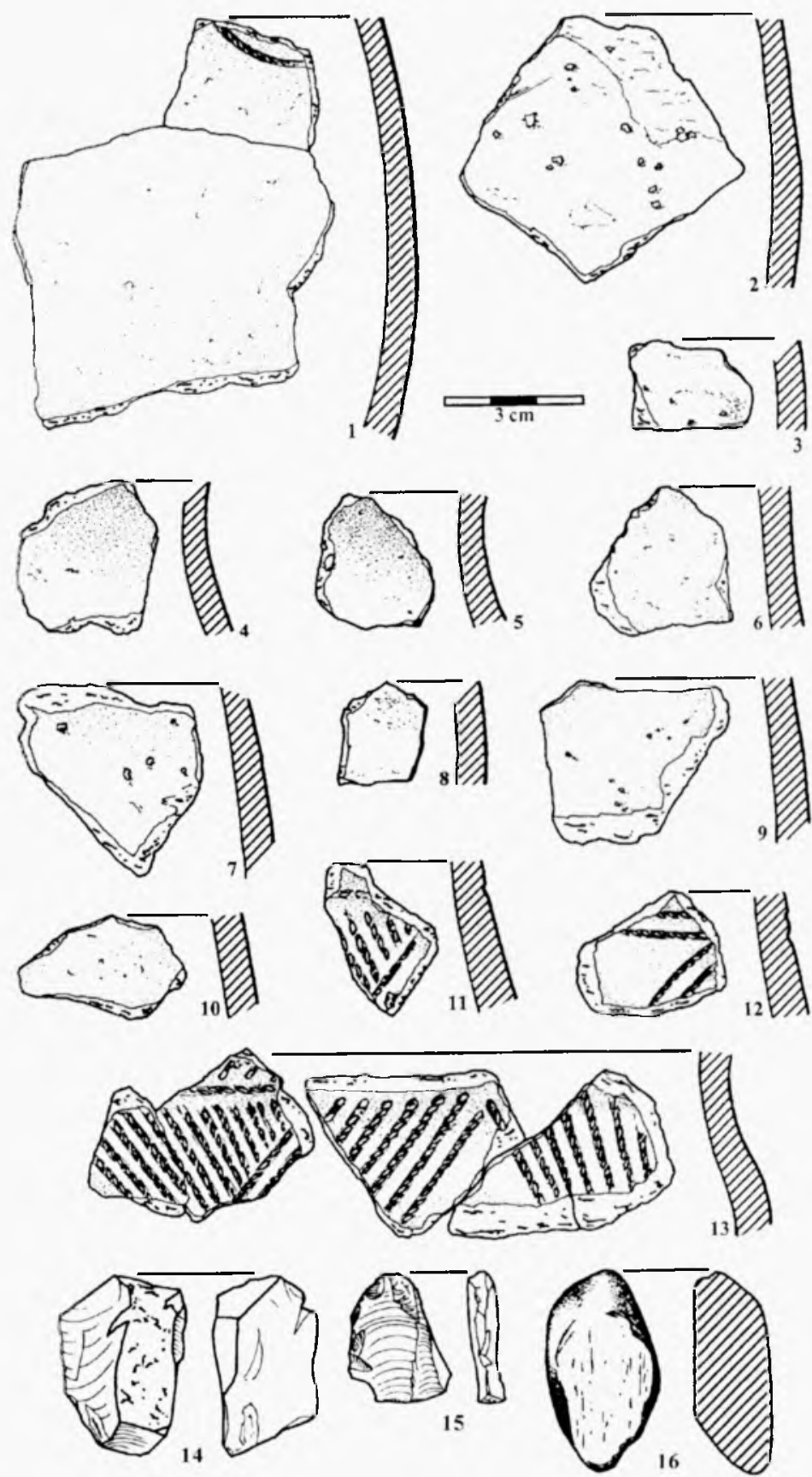

Ryc. 3. Poznań-Nowe Miasto, stan. 314. Ceramika naczyniowa z paleniska (ob. 1). Rys. M. Żółkiewski

Fig. 3. Poznań-Nowe Miasto, site 314. Pottery from hearth (feature 1). Drawing: M. Żółkiewski 
ułamków ceramiki, częściowo wytarte odciski, a przede wszystkim wypał miały decydujący wpływ na liczbę i dokładność pomiarów, co zaważyło - i mamy tego świadomość - na ostatecznych wnioskach. Wyjątkowa wartość poznawcza eksperymentu zdopingowała do wykonania analiz „tekstyliów produkcyjnych”, które - jak się okazało szczątkowo zachowały się na obydwóch ściankach.

\section{SZNUR}

Na ściance amfory (?) rozpoznano odciski sznura w układzie wiszących trójkątów. Negatywy (poziome i ukośne) zachowaly się w mniej lub bardziej regularnych odstępach, średnio co $1,611 \mathrm{~mm}$. Niezależnie od krzywizny na odcinku brzusiec/szyjka, odległości pomiędzy nimi nie przekraczały 1,106-2,133 mm (tab. 1); więcej - sznur odciśnięty został na tę samą głębokość. Nie wiadomo, z jakiego surowca był wykonany, jednak udało się dokonać pomiaru pojedynczych włókien elementarnych, które nie przekroczyły grubości $0,016 \mathrm{~mm}$. Sznur, jak się okazało, przygotowano nie z dwóch, lecz z pięciu nitek, trzech skręconych w lewo ( $\mathrm{S}$ - o średnicach $0,361-0,492 \mathrm{~mm}$ ) $i$ dwóch w prawo $(Z-0,328-0,410 \mathrm{~mm})-\mathrm{z}$ tym, że wysoce problematyczne jest odczytanie skrętu $Z$. Wszystkie nici skręcono pod kątem $45-65^{\circ}$ w lewo (S/3S/2Z? - grubość obliczona na podstawie negatywu $2,211 \mathrm{~mm})^{7}$. Dzięki ścisłemu spleceniu pięciu nici uzyskano pozorny efekt dwudzielnego wyrobu (fot. 1, 2). Sznur, pocięty na odpowiednie kawałki $(0,9--3,2 \mathrm{~cm}$ na badanych fragmentach) zapewne przyszyto do ,tkaniny siatkowej", tworząc w ten sposób misterny szablon tekstylny, którym ozdobiono naczynie (ryc. 4).

Tabela 1

Poznań-Nowe Miasto, stan. 314, obiekt 1. Wyniki pomiarów odcisków sznura na fragmentach ceramiki KAK

\begin{tabular}{|c|c|c|c|c|}
\hline Sznurek & Grubość calkowita & Grubość nitek & Skręt & Surowiec \\
\hline \multirow[t]{2}{*}{ Sznurek } & \multirow[t]{2}{*}{$\begin{array}{l}1,810-2,760 \mathrm{~mm} \\
\text { śred. } 2,221 \mathrm{~mm}\end{array}$} & $\begin{array}{l}0,328 \mathrm{~mm}(\mathrm{Z} ?) \\
0,361 \mathrm{~mm}(\mathrm{~S}) \\
0,410 \mathrm{~mm}(\mathrm{Z} ?) \\
0,443 \mathrm{~mm}(\mathrm{~S}) \\
0,492 \mathrm{~mm} \text { (S) }\end{array}$ & \multirow[t]{2}{*}{$\begin{array}{l}\mathrm{S} / 3 \mathrm{~S} / 2 \mathrm{Z} \\
\text { kąt } 45-65^{\circ}\end{array}$} & \multirow[t]{2}{*}{$\begin{array}{l}\text { ? grub. wh. element } \\
0,016 \mathrm{~mm}(?)\end{array}$} \\
\hline & & $\begin{array}{l}2,034 \mathrm{~mm} \\
\text { (na podst. odcisków } \\
\text { w jednym negatywie) }\end{array}$ & & \\
\hline
\end{tabular}

Suma pomiarów grubości nitek w jednym odcisku sznura jest mniejsza i wynosi $2,034 \mathrm{~mm}$. 


\section{WYRÓB SIATKOWY}

Niekompletne, częściowo wytarte i przepalone resztki siatki zarejestrowano pomiędzy odciskami sznura i na niezdobionej powierzchni brzuśca. Poszczególne fragmenty po wypale i okresie eksploatacji naczynia - zachowały się śladowo ${ }^{8}$. System nici był w takim stopniu czytelny, że - pomimo określonych zastrzeżeń - negatywy i pozytywy przędzy (?) uznaliśmy za wyroby podobne do typu sprang (fot. 3$)^{9}$. Na ściance zachowały się:

- ślady pojedynczych włókien, o grubości 0,013-0,016 mm (średnia 0,015 mm);

- średnia grubość przędzy, skręconej w lewo (S) wynosiła $0,16 \mathrm{~mm}$ (wynik na pewno zaniżony; najgrubsze nici o średnicy $0,2 \mathrm{~mm}$ );

- stwierdzono $18-20 \mathrm{nici} / \mathrm{cm}(?) ;$

- odstępy pomiędzy oczkami siatki około $0,375 \mathrm{~mm}$ (otwory przy oczkach sugerują mocne naciagnięcie „tkaniny” - tab. 2).

Przedstawione dane stanowią interesujący przyczynek do studiów z jednej strony nad neolitycznymi tekstyliami ${ }^{10}$, $\mathrm{z}$ drugiej zaś wskazują na bardzo praktyczne i efektywne wykorzystanie wyrobów siatkowych podczas formowania i ostatecznego wykończenia bryły przez wytwórcę ${ }^{11}$. Okazuje się bowiem, że wyrób typu sprang (lub wykonany w technice igłowej) nie wymagał właściwie żadnych skomplikowanych narzędzi ${ }^{12}$ i sprawdził się jako element elastycznego szablonu oraz - jak się wydaje - skutecznie zapobiegał odkształcaniu się ścianki od wewnątrz (płytkie negatywy).

Tabela 2

Poznań-Nowe Miasto, stan. 314, obiekt 1. Wyniki pomiarów odcisków wyrobu siatkowego na fragmentach ceramiki KAK

\begin{tabular}{c|c|c|c|c}
\hline Osnowa & Gęstość & Grubość przędzy & Skręt & Surowiec \\
\hline Osnowa & ok. $18-20$ nici & $0,099-0,200 \mathrm{~mm}$ & S & $?$ grub. wł. element. \\
& $1 \mathrm{~cm}(?)$ & śred. $0,160 \mathrm{~mm}$ & kąt $40-45^{\circ}$ & $0,013-0,016 \mathrm{~mm}$ \\
& & & & śred. $0,015 \mathrm{~mm}$ \\
\hline
\end{tabular}

\section{SZABLON}

Przypuszczalnie był to zatem albo dłuższy kawałek wyrobu siatkowego, albo rodzaj przepaski, szerokości około $3,5 \mathrm{~cm}$, na którą naszyto ukośnie 12-13 sznurków i dwa (?) w poziomie (ryc. 4). Szablon tekstylny był tak elastyczny, że stosunkowo łatwo dociskano go na wypukłej i wklęsłej powierzchni ścianki, zachowując przy tym prawie taką

${ }^{8}$ Easzczewska 1966 , ryc. 10 .

${ }^{9}$ Hald 1950, s. 257, fig. 258, h.; Moszyński 1967, s. 331; Maik 1988, s. 44, 45; Seiler-Baldinger 1994, s. 51 i n.; Sikorski 2001.

${ }^{10}$ Laszczewska 1966 , s. 22 n.

${ }^{11}$ Wiślański 1966, s. 25.

${ }^{12}$ Sailer-Baldinger 1994 , s. $7,8,51$ 

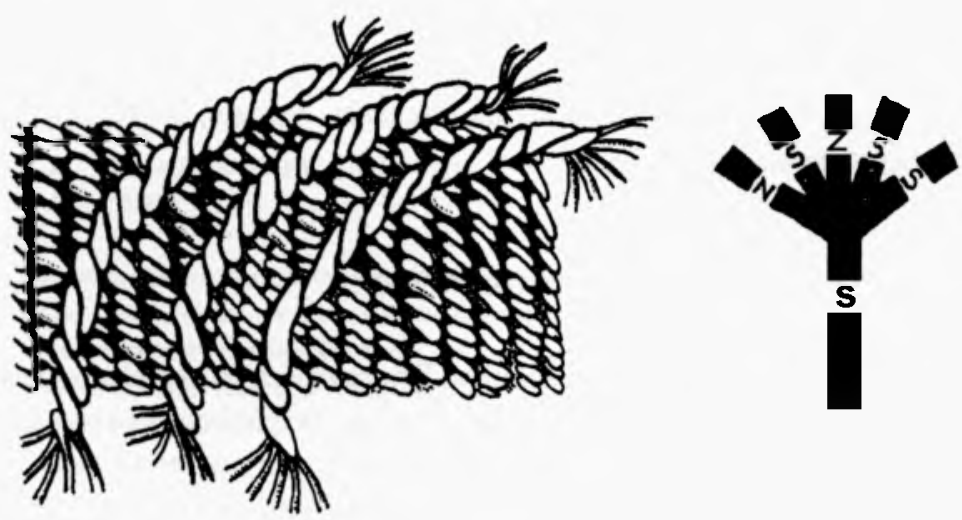

Ryc. 4. Poznań-Nowe Miasto, stan. 314. Rekonstrukcja szablonu tekstylnego. Rys. K. Trawińska

Fig. 4. Poznań-Nowe Miasto, site 314. Reconstruction of a textile template. Drawing: K. Trawińska

samą głębokość odciskanego wzoru. Łatwość i szybkość wykonania tak pracochłonnej zdobiny, precyzja (odstępy między sznurami rzędu 1,6 mm) i brak jakichkolwiek odcisków palców wytwórcy wskazują na wykorzystanie takiego właśnie szablonu. Nasza obserwacja powinna być zweryfikowana na całych zdobionych pojemnikach KAK, lecz już teraz wydaje się, że odnotowaliśmy kolejny przykład zastosowania tekstyliów przy produkcji ceramiki ${ }^{13}$.

\section{DATOWANIE}

Na podstawie cech techno-stylistycznych fragmentów górnej części brzuśca i szyjki amfory(?), zdobionej charakterystycznym motywem sznura wielodzielnego wolno przypuszczać, że nawiązują one do zachodnich elementów KAK. Zgodnie z sugestiami T. Wiślańskiego ${ }^{14}$ i nowszymi ustaleniami innych autorów, odnoszącymi się do Kujaw, podobne zdobiny datowane są w horyzoncie znalezisk z 3250/3100$-2400 / 2150$ BC (2500-1900/1850 conv. $)^{15}$. Autorzy wstępnego opracowania wyników datują obiekt I, ze stan. 314 w Poznaniu-Nowym Mieście, na III fazę rozwoju KAK w Wielkopolsce (tj. $2200-2000$ p.n.e.) ${ }^{16}$. Jednak wydaje się, że na tle przyjętych ustaleń chronologicznych należy się zastanowić nad niektórymi cechami zdobniczymi KPL, KAK, a także - na terenie Niemiec i Polski - $\mathrm{KCSZ}^{17}$ oraz późniejszych

\footnotetext{
${ }^{13}$ Hołubowicz 1950, s. 145, 161, 162; 1965, s. 23-26; Laszczewska 1966, s. 23 n.; Moszyński 1967, s. 362, 363; Kłoczko 1998; Makarowicz 1998, s. 42, ryc. 7, 17; Sikorski 2003.

${ }^{14}$ Wiślański 1979 a, s. $267-287$.

${ }^{15}$ Czerniak 1994, s. 85, 142-144; Szmyt 1996, s. 233-235, ryc. 80:8.

${ }^{16}$ Michałowski, Rogalski, Żółkiewski 2001.

${ }^{17}$ Wiślański 1966 , s. 87 ; Szmyt 1996 , s. 74,75 ; Kurzawa 2001, s. $180,181$.
} 
jednostek kulturowych ${ }^{18}$, jako że odciski diagnostycznego sznura „dwudzielnego” (faktycznie pięciodzielnego - fot. 1,2) i „trójdzielnego”, a także sposób realizacji wątków powinny zostać zweryfikowane na większej, bardziej reprezentatywnej serii ceramiki naczyniowej.

\section{PODSUMOWANIE}

Pomimo niepewnych wyników pomiarów laboratoryjnych (spieki, wypłycenia zagłębień negatywowych, starcia powierzchniowe, ślady eksploatacji) na fragmentach amfory (?) KAK, zasygnalizowaliśmy kilka nowych informacji zarówno o zakresie czynności technicznych wytwórcy lepiącego z gliny, jak i wykorzystania niekonwencjonalnego tekstylnego szablonu zdobniczego, który - jak można zakładać - mógł być szeroko stosowany nie tylko w tym okresie (ryc. 4). Ponadto udało się poświadczyć ślady „starej” techniki siatkowej, co - wobec szczupłej bazy źródłowej - ma niebagatelne znaczenie dla historii włókiennictwa ${ }^{19}$. Ustalenia te pozwoliły przede wszystkim na weryfikację obiegowych ustalen dotyczących sznura dwudzielnego, będącego diagnostycznym wyznacznikiem techno-stylistycznym w badaniach nad ceramiką neolityczną, rozważając nadto inne, pozornie nieuchwytne, przejawy działalności przędzalniczej i tkackiej w obrębie gospodarstwa domowego i w obrządku pogrzebowym (przęśliki, ciężarki tkackie, szpule, negatywy tkanin, „tasiemek tekstylnych”, siatek, sznurów, mat na ceramice i ryty na kamieniach megalitycznych) ${ }^{20}$.

\section{BIBLIOGRAFIA}

Czebreszuk J., Makarowicz P., Szmyt M.

1998 Sieć powiqzań genetycznych spolecznośći trzcinieckiego kręgu kulturowego na Kujawach [Sum. The network of genetic ties of the Kujawy branch of the Trzciniec Cultural Circle], (w:) ,Trzciniec" - system kulturowy czy interkulturowy proces? (red. A. Kośko, J. Czebreszuk), Poznań, s. $121-134$.

Czerniak L.

1994 Wczesny i środkowy okres neolitu na Kujawach 5400-3650 p.n.e. [Sum.: Early and Middle Period of the Neolithic in Kuiavia], Poznan.

Hald $M$.

1950 Olddanske tekstiler. Komparative Tekstil- og Dragthistoriske Studier paa Grundlag af Mosefund og Gravfund fra Jernalderen [Sum. Ancient Danish textiles], København.

Hayes J.W.

1977 Some Etruscan Textile Remains in the Royal Ontario Museum, (w:) Studies in Textile History (ed. V. Gervers), Ontario, s. 144-148.

${ }^{18}$ Czebreszuk, Makarowicz, Szmyt 1998, s. 127.

${ }^{19}$ Hald 1950; Kamińska, Nahlik 1958; Łaszczewska 1966; Turnau 1979, 1987; Maik 1988; Makkay 2001.

${ }^{20}$ W iślański 1979a, s. 287; 1979b, s. 243, 244: K łoczko 1998, s. 332, ris. 3; M üller 1999, s. 201 in. 
Hołubowicz W.

1950 Garncarstwo wiejskie zachodnich terenów Biatorusi, Torun.

1965 Garncarstwo wczesnośredniowieczne Slowian, „Studia Archeologiczne” t. I.

Kamińska J., Nahlik A.

1958 Wlókiennictwo gdańskie w X-XIII wieku [Sod. Gdanskaja tekstilnaja promyszlennost' X-XIII viekov], Łódź.

Kłoczko L.S.

1998 Żenskij kostium v Pravobiereznoj Ukrainie po materiatam ukraszenija tszinieckoj i komarovskoj kultur [Sum.: Women's clothes in the Right-Bank Ukraine as reconstructed on the basis of the Komarowo and Trzciniec Cultures], (w:) „Trzciniec” - system kulturowy czy interkulturowy proces? (red. A. Kośko, J. Czebreszuk), Poznań, s. 329-336.

Kośk o A.

1981 Udzial potudniowo-wschodnioeuropejskich wzorców kulturowych w rozwoju nizowych spoteczeństw kultury pucharów lejkowatych [Zus.: Beitrag der süd-osteuropäischer Kulturvorlagen zur Entwicklung der Tieflandgesellschaften der Trichterbecherkultur. Die Mątwy-Gruppe], Poznan.

Kurzawa J.

2001 Zagadnienie najwcześniejszych faz kultury ceramiki szmurowej na Nizinie Wielkopolsko-Kujawskiej. Problem tła genetycznego spoteczności kultury pucharów lejkowatych, Poznań.

Laszczewska T.

1965 Pradzieje wtókiennictwa. Zarys historii wiokiennictwa na ziemiach polskich do końca XVIII wie$k u$, red. J. Kamińska i I. Turnau, Wrocław-Warszawa-Kraków, s. 21-53.

Maik J.

1988 Wyroby wlokiennicze na Pomorzu z okresu rzymskiego ze średniowiecza [Sum.: The textiles of Pomerania in the Roman Period and in the Middle Ages], Wrocław-Warszawa-Kraków-Gdańsk-Łódź.

Makarowicz P.

1998 Kujawski nurt trzcinieckiego kregu kulturowego - podstawy taksonomiczne [Sum.: Taxonomic foundations of the Cuiavian variety of the Trzciniec Cultural Circle], (w:) "Trzciniec" - system kulturowy czy interkulturowy proces? (red. A. Kośko, J. Czebreszuk), Poznań, s. 33-60.

Makkay J.

1998 Textile impressions and related finds of the Early Neolithic Körös culture in Hungary. With an Appendix: The ritual spinning, Budapest.

Malinowski T.

1985 Wielkopolska $w$ otchtani wieków, Poznań.

Michałowski A., Rogalski B., Żółkiewski M.

2001 Sprawozdanie z archeologicznych nadzorów wyprzedzajacych, wykonanych w roku 2001 na trasie autostrady $A 2$ (obwodnica Poznania), Poznań (maszynopis).

Moszyński K.

1967 Kultura ludowa Stowian. Kultura materialna, t. I, Warszawa.

Munsell

1973 Munsell Soil Color Charts, Baltimore.

Müller D.W

1999 Petroglyphen aus mittelneolithischen Gräbern von Sachsen-Anhalt. Herkunft, Datierung und Bedeutung, ,Studien zur Megalithik. Forschungsstand und ethnoarchäologische Perspektiven"

(Hrsg. K.W. Beinhauer, G. Cooney, Ch.E. Guksch, S. Kus), Mannheim-Weißbach, s. 199-214.

Seiler-Baldinger A.

1994 Textiles a classification of techniques, Bathurst.

Sikorski A.

2001 Analiza pozostatości tekstyliów z później epoki brazu i wczesnej epoki żelaza z Konina-Grójca [Sum.: Analysis of textile traces from the Late Bronze and Early Iron Periods from Konin-Grójec], „Sprawozdania Archeologiczne” t. 53, s. 377-389. 
2003 Analiza odcisków tkanin na IX-XI-wiecznej ceramice naczyniowej z Góry, gm. Pobiedziska. woj. wielkopolskie, stan. 1 [Sum.: An analysis of fabrics impressions on pottery from the $9^{\text {th }}$ to $11^{\text {th }}$ century from Góra, site 1, Pobiedziska commune, Wielkopolska voivodeship], „Folia Praehistorica Posnaniensia" t. X/XI, s. 243-254.

Szmyt M.

1994 Spoleczności kultury amfor kulistych na Kujawach [Sum. Communities of the Globular Amphora Culture in Kuiavia], Poznań.

Turnau I.

1979 Historia dziewiarstwa europejskiego do poczqtku XIX wieku [Sum.: The history of knitting in Europe till the begonning of the $19^{\text {th }}$ century], Wroclaw-Warszawa-Kraków-Gdańsk.

1987 Historia europejskiego wlókiennictwa odzieżowego od XII do XVIII w. [Sum. The history of European textile for dress between thirteenth and eighteenth centuries], Wrocław-Warszawa-Kraków-Gdańsk-Łódź.

Wiślański T.

1964 Kultura amfor kulistych w Polsce pótnocno-zachodniej [Sum. Globular Amphorae Culture in North-Western Poland], Wroclaw-Warszawa-Kraków.

1979a Dalszy rozwój ludów neolitycznych. Plemiona kultury amfor kulistych, (w:) Prahistoria ziem polskich, t. II: Neolit (red. W. Hensel, T. Wiślański), Wrocław-Warszawa-Kraków-Gdańsk, s. 261-299.

1979b Ksztaltowanie się miejscowych kultur rolniczo-hodowlanych. Plemiona kultury pucharów lejkowatych, (w:) Prahistoria ziem polskich, t. II: Neolit (red. W. Hensel, T. Wiślański), Wrocław-Warszawa-Kraków-Gdańsk, s. 164-260.

\section{A CORDED ORNAMENT ON THE GLOBULAR AMPHORAE CULTURE POTTERY FROM POZNAŃ-NOWE MIASTO, SITE 314}

\section{Summary}

Archaeological data lacks textiles that, being organic materials, are rarely preserved. However, there is a number of plaiting, meshes, and other textile impressions on prehistoric ceramics, in particular from earlier periods.

Particularly interesting are negatives of decoration made in a net and cord technique, which is characteristic motif of Neolithic pottery, discovered during rescue excavations on the Poznań ring, which itself is a section of the A2 highway. An area of more than 40 ares was opened up at Poznan-Nowe Miasto, site 314. One flint core and flake along with 24 pottery sherds (from 3 different vessels) were discovered in one of the features (hearth). These artefacts are linked to a seasonal camp of the Globular Amphorae Culture community.

Laboratory analysis comprised 7 fragments from the upper part of amphorae (?) (Fig. 2, 11-13). A wall thickness of the pot, fired in oxidising atmosphere, ranged between 0.7 and $0.9 \mathrm{~cm}$.

Initial analysis resulted in a number of suppositions. Firstly, there were no finger (or nail) impressions on or near the 'baroque' corded decoration (placed on a natural curvature of vessel belly and neck), which seems to be rather inevitable while placing a cord every $2 \mathrm{~mm}$ (on a wet surface of large vessel). Secondly, there was a precise layout and space between particular impressions irrespective of an angle of ornament placements and decorative element joints. Thirdly, a wall texture between cord impressions appeared to be too plain (Photo 1). In order to explain these issues, a number of systematic observations, using stereoscopic microscope NIKON SMZ 1000, was conducted in Institute of Environmental Biology and Institute of Prehistory at Adam Mickiewicz University. Altogether, more than 200 measurements and laboratory estimations were taken (Tab. 1, 2).

This analysis resulted in recognition of cord impressions in the form of hanging triangles on an amphorae (?) wall. Particular negatives (both horizontal and diagonal) were placed in more or less regular spaces from 
each other (ca. $1.6111 \mathrm{~mm}$ ). Irrespective to curvature of vessel belly or neck, spaces between them did not exceed 1,106-2,133 mm (Tab. 1) and a cord was impressed to the very same depth. A cord was made out of five, not two, strands. Three of them were left-sidedly twisted ( $\mathrm{S}$ - diameter ca. 0.361-0.492 mm) while two others had right-sided twists $(Z-0.328-0.41 \mathrm{~mm}$ ). However, one needs to admit that recognition of a $Z$ twist is highly problematic. All strands were twisted leftwards at an angle of 45-65 degree ( $\mathrm{S} / 3 \mathrm{~S} 2 \mathrm{Z}$ ? - a thickness calculated on the basis of a 2.211 negative). Relatively close twisting of all 5 strands resulted in seemingly two-stranded ornament (Photo 1, 2).

At the same time, incomplete, partly shabby and burnt fragments of net was discovered between cord impressions and on undecorated vessel surface. A strands system was recognisable to degree that - despite some reservations - led us to define yam (?) negatives and positives as similar to sprang type. A left-sided yam (S) was approximately $0.16 \mathrm{~m}$ in thickness (this is certainly a considerably lowered calculation); spaces between net meshes had ca. $0.375 \mathrm{~mm}$; and holes near the meshes indicate strong stretching of a 'fabric' (Photo 3; Tab. 2).

We are probably dealing here with longer piece of a net item or a kind of band of $3.5 \mathrm{~cm}$ in diameter onto which 12-13 diagonal and 2 (?) horizontal strands were sewn (Fig. 4). A textile template was amply elastic to be casily press down to both concave and convex wall surface and produce equally deep impression. An ease and fastness of making this labour-intensive decoration, its precision (spaces between cords of ca. $1.6 \mathrm{~mm}$ ) and lack of any kind of finger impressions is indicative of use of the kind of template.

Irrespective to "uncertain' results of laboratory measurements of the Globular Amphorae Culture pottery sherd, we drew attention to a few facts regarding pottery manufacture (use of a five-stranded cord for vessel decoration and not a two-stranded one as previously thought) as well as use of unconventional textile template, which - one can assume - was widely applied by communities of the Funnel Beaker, Globular Amphorae and Corded Ware Cultures.

Translated by Arkadiusz Marciniak 